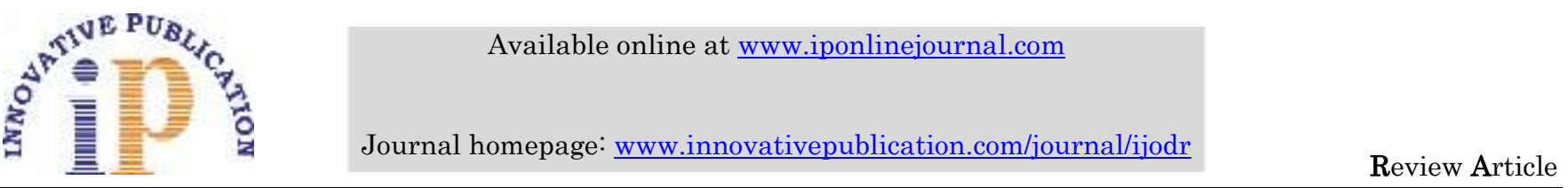

\title{
Borderline cases in orthodontics-A review
}

\author{
Priti Shukla ${ }^{1 *}$, Rachit Thakral ${ }^{2}$, Shraddha Gupta ${ }^{3}$, Amit Nagar ${ }^{4}$ \\ ${ }^{1,3}$ Senior Resident, ${ }^{2}$ Senior lecturer, ${ }^{4}$ Professor, ${ }^{\mathbf{1 - 4}}$ Dept. of Orthodontics and Dentofacial Orthopaedics, ${ }^{\mathbf{1 , 3 , 4}}$ King George Medical University \\ Lucknow, ${ }^{2}$ I.T.S Centre for Dental Studies and Research Ghaziyabad Uttar Pradesh, India
}

\begin{abstract}
A borderline case is one for which, different skilled orthodontists when given the opportunity to examine the clinical records independently disagree for a single definitive treatment plan.

The borderline problem must be broken down into its etiological components as Borderline orthopedic problem of skeletal disharmony, Orthodontic problem of arch length discrepancy, Malalignment due to localized migration of teeth, Combination of all the three.
\end{abstract}

Keywords: Non extraction treatment extraction vs non extraction debate, Camouflage treatment, Borderline orthodontics, Proximal stripping.

\section{Introduction}

The borderline patient is that individual caught between definitive extraction and non-extraction; "Empirical evidence of uncertainty exists with these patients." ${ }^{1}$ But when "some skilled clinicians... would be likely to make opposite decisions" and disagree "as to whether extraction or non-extraction therapy was the optimum treatment", idea that there exists only one, single-best treatment should drive further investigation to establish diagnostic methods to aid the borderline case.

\section{Diagnosis of borderline cases Clinical Examination ${ }^{3}$}

1. Lip separation - increases with tooth prominence.

2. Thick, full lips.

3. Size of nose and chin.

4. Lip strain i.e. lack of well defined labiomental sulcus.

5. Profile: Mild concave / convex.

\section{Model Analysis ${ }^{3}$}

Ashley Howe's Analysis, Carey's/ Arch perimeter Analysis, Peck and Peck Analysis, Bolton Analysis

\section{Cephalometric Evaluation $^{3}$}

Tweed diagnostic triangle, ANB difference, Facial angle, Relationship of the facial line to lower incisors, Mandibular plane - occiput relation, Amount of chin point measured from NB-NPog.

\section{Factors affecting treatment planning of borderline cases Compliance ${ }^{4}$}

Certain types of malocclusion, require additional compliance to ensure treatment success, so treatment plans based on patient-dependent mechanics (like intermaxillary elastics, use of headgears etc.) may have their treatment outcome jeopardized if the patient failed to respond accordingly.

\section{Tooth-Arch discrepancy ${ }^{3}$}

This discrepancy should be evaluated in both the upper and lower arches. When orthodontists are faced with a marked negative tooth-arch discrepancy (TAD) in the lower arch, they will be hard pressed to treat the patient by performing tooth extractions. Small negative discrepancies can, in most cases, be treated without extractions. Thus, space can be obtained by using leeway space (if still possible), stripping, correction of pronounced mesial tipping of lower posterior teeth and small expansions and/or protrusions ${ }^{3}$.

\section{Cephalometric discrepancy $(C D)$ and facial profile ${ }^{5}$}

In situations of pronounced labial tipping of the incisors with a high $\mathrm{CD}$ and expressive facial convexity, extractions are often necessary to retract these incisors, improving the patient's profile. The current trend in orthodontic diagnosis is to focus more on soft tissue features and rely less on cephalometric measurements. Therefore, sometimes a case is finished with protrusive incisors so as not to alter a satisfactory profile.

Skeletal age (growth) and anteroposterior relationships ${ }^{3}$ Maximum pubertal growth spurt occurs approximately at around 11-12 years in girls and 13-14 years in boys, subject to individual variations. If a malocclusion can be corrected with growth response (growth redirection); clinicians can handle the case without extractions.

\section{Dental asymmetry ${ }^{6,7,8}$}

Patients presenting with severe dental midline deviation relative to the face (especially in the lower arch) require tooth extractions. Small asymmetries can be corrected with

\footnotetext{
*Corresponding Author: Priti Shukla, Dept. of Orthodontics and Dentofacial Orthopaedics, King George Medical University Lucknow, Uttar Pradesh, India

Email: drpritipankaj@gmail.com

http://doi.org/10.18231/j.ijodr.2019.017
} 
intermaxillary elastics or mini-implants (in some cases, unilateral mechanics), asymmetric extractions, stripping.

\section{Facial pattern ${ }^{9,10}$}

Dolichofacial patients have hypotonic facial muscles in the vertical direction. ${ }^{10}$ Brachyfacial patients are not as prone to anchorage loss due to hypertonic masticatory muscles that hinder tooth movement. Normally dolichocephalics experience greater anchorage loss than brachycephalics, hence extra care must be taken during space closure.

\section{Pathologies $^{11}$}

Patients can have half-formed teeth, agenesis, ectopias, abnormal shapes or even carious processes, and endodontic lesions that indicate tooth extraction. During diagnosis these conditions should be considered as they may change-in certain situations-the choice of the tooth or teeth to be extracted $^{12}$.

\section{Treatment modalities of borderline cases}

Management of borderline skeletal malocclusions in growing individuals

Functional appliances ${ }^{13,14}$

As rule, Class II cases treated with the fixed functional appliances requires a subsequent dental alignment treatment phase with a multibracket appliance.

\section{Treatment effects on the dentofacial complex}

The improvement in sagittal occlusal relationships - equal result of skeletal and dental changes. ${ }^{15}$

\section{Occlusal changes ${ }^{15,16}$}

The dental changes - result of anchorage loss in the maxillary and mandibular arches.

Posteriorly directed forces in maxilla - distalise maxillary teeth while anteriorly directed forces in mandible - mesialise mandibular teeth.

\section{Sagittal cephalometric changes}

1. Stimulates mandibular and to a lesser extent restrains maxillary growth. (Headgear effect)

2. The forward position of mandible - result of increase in mandibular length [about three times increase in mandibular length] which in turn is due to condylar growth stimulation in response to bite jumping. ${ }^{15,16}$

\section{Condyle-fossa relationships}

1. The mandible as a whole displaced anteriorly due to remodeling process in the articular fossa.

2. Temporomandibular joint radiographs taken before and after Herbst treatment revealed unchanged condylar relationships with no adverse structural changes in the condyle, fossa, and/or articular tubercle. ${ }^{16}$

\section{Treatments effects on the masticatory system}

1. Occlusal contact only between anterior teeth - chewing difficulties for 7 to 10 days.
2. Reduced masticatory efficiency during first 3 months of treatment. $^{15}$

\section{Orthopaedic appliances}

Heavy forces applied causes compression of PDL, so teeth if moved, it is by undermining resorption. Orthopaedic forces are interrupted \& intermittent in nature-applied for about 10-12 hours a day. Tooth movement tendency is decreased since body restricts normal circulation for about 12-14 hrs when the appliance is not worm. But the total effect on periosteal sutures \& maxillary growth centres is not lost, since the membranous bones has been under restrictive force for about 10-12 hrs. Heavy interrupted forces thus produce significant basal bone effect with minimum response of teeth to move.Orthopaedic forces produces Primary Displacement of the bones in nasomaxillary complex and initiate Bone remodeling at the sutural interfaces ${ }^{17-19}$

\section{Clinical application of orthopedic forces In class I malocclusion}

When there is arch length / tooth size discrepancy problem patient is treated in Early Mixed Dentition by either serial extraction or orthopaedic expansion. Head - gears are used when maximum anchorage is needed to maintain the existing Arch Length.

\section{In class II malocclusion}

Headgear is used for four main purposes

1. Anchorage control

2. Tooth movement

3. Orthopaedic changes

4. Controlling the cant of occlusal plane.

\section{Maxillary skeletal protrusion}

Is treated by E.O traction.

Cervical (low pull) face bow is used in patients with decreased VD (Kloehn, Graber, Weislander)

Occipital (high pull) face bow: Used in patients with increased VD.

\section{Maxillary skeletal retrusion}

They have increased lower facial height, a steep mandibular plane angle, retruded position of chin point. Can be treated by vertical pull chin cup which produces upward $\&$ forward movement of maxilla \& counter clockwise rotation of the mandible. $^{19}$

\section{Maxillary dento alveolar protrusion}

Flared upper incisors are retracted using a High-Pull HG or Straight pull combined with J-Hooks or a closing Arch supported by HG.

\section{Mandibular skeletal retrusion}

Treated by functional jaw orthopedics which includes forward posturing of the mandible. Eg. FR2, Bionator, 
Herbst. In recent years, RME appliances are used for spontaneous correction of some C1ass II problems. ${ }^{17}$

\section{Use of orthopedic forces in class II backward rotators}

1. In mixed dentition open-bite patients: Upper first permanent molar are included with Occipital pull HG, inclination of molars controlled using TPA. Lower molar extrusion prevented by adding a vertical - pull chin cup. As open bite closes - mandible hinges upward and lower facial height decreased. Deciduous teeth extracted after $3 \mathrm{~mm}$ intrusion of upper permanent molar have taken place.

2. Useful in Extraction cases: remove all 4 first premolar and use a vertical pull chin cup with 16 ounces of force directed anteriorly - 12 hours a day.

a. Closes the mandibular plane angle and decreases the facial height

b. Max sutures are pressure sensitive so cause some intrusion of the maxilla.

c. Slight change in shape of condylar neck which curves forward.

d. Posterior teeth- eruption prevented.

3. Use of mandibular bite blocks combined with vertical pull chin cup. Produces favourable holding of the vertical height throughout the growth period, causes intrusion of posteriors hinging the mandibular plane in a closed or counter clockwise direction and closure of anterior open bites.

4. Intrusive forces with fully banded appliance along with occipital pull HG help in controlling the VD. ${ }^{20}$

\section{In C1 III malocclusion}

CL III MO may be due to maxillary deficiency or mandibular excess.

\section{Treatment of maxillary deficiency}

1. Reverse pull head gear or protraction head gear by Hickham

2. Face mask by Delaire

3. Sub-orbital protraction appliance: Developed by Grummons, Zygomatic arch areas support the appliance, no force exerted on TMJ. Easy to adjust and comfortable to wear during sleep.

4. Maxillary protraction bow appliance (MPBA Therapy)

\section{Extra oral forces in functional appliances}

Activator - Head gear combination:

Early elimination of restrictive muscle forces is mixed dentition if possible is biologically sound. According to Stockli \& Teuscher (1994): Prime target of this combination is to restrict developmental contribution towards skeletal CI II and harmonize Max / Mand relationship.

Occlusion should be unlocked and proper direction of orthopaedic force selected so that there is effective restraint of max. growth and translation - permits favourable auto rotation of the mandible up and forward. So there is no interference with normal mandibular growth pattern. This is opposite to that of the undesired KLOEHN EFFECT. ${ }^{21}$ Stock Fish, Janson, Hickam - uses the KINETOR (skeletonized elastic activater) and Janson - combines BIONATR \& EO Force

\section{EO force in frankel appliance}

Little function occurs during sleep. So EO force is used in CI II MO with maxillary protrusion, appliance is anchored onto the maxilla Light Oblique / Vertical Pull Force is applied. Buccal tube is embedded in the Buccal shield.

\section{Orthopaedic traction in twin Block}

Retractive and intrusive forces can be applied to Twin Block by addition of Head Gear tubes to molars which apply retractive forces to maxilla. Can be combined with intermaxillary traction using a modified concorde face bow to advance the mandible by orthopaedic traction in addition to functional correction by twin block.

\section{Management of borderline dentoalveolar malocclusions in growing/ non-growing individuals Proximal stripping}

Black was amongst the pioneers who described natural slenderization in 1902. Ballard first described a technique to reduce the tooth material by reducing the enamel. Peck called this procedure as reproximation. ${ }^{22}$ Begg's showed that incidence of malocclusion was low in the dentition of the aboriginals. He reasoned that constant wearing of the tooth material due to rough diet was the main reason for the absence of the malocclusion.

\section{Various techniques}

1. Abrasive strips: it is too laborious and time consuming.

2. Hand piece mounted reducing discs : because of its close proximity with tongue and other soft tissue like lips and cheek they can be dangerous. ${ }^{23}$

3. Air-rotar stripping: first described by Sheridan. Air rotar stripping involves the use of a fine air rotar diamond cutting bur attached to the headpiece to reduce interproximal enamel for alleviation of mild to moderate crowding. The space generated by air-rotar striping does not have to be estimated. It can be measured with commercially available gauges. A conservative guideline is to remove no more than $.75 \mathrm{~mm}$ of interproximal enamel between the anterior contact points and no more than $1 \mathrm{~mm}$ from the posterior contact points. ${ }^{24}$

4. Intensive Orthostrip system $(\mathrm{GAC})^{24}$ : It involves the use of hand piece driven abrasive strips with different configuration and abrasive potential the instrument removes enamel by back and forth shuttle action. Flexible blades (proxy shape) are also used to contour and smooth the reduced proximal surface with abrasive grain size of different dimensions. 
Interproximal reduction can be useful in preventing relapse in lower anterior because point contacts are reduced to surface contacts and prevents sliding of the teeth.

\section{Molar Distalization ${ }^{25,26}$ \\ Indications}

Straight profile, Normal and healthy temporomandibular joint, Correct mandible to maxillary relationship.

Skeletally, Class I skeletal base, Normal / short lower facial height, Maxilla with normal transverse width, Brachycephalic growth pattern, Skeletal closed bite.

Dentally, Class II molar relationship, Deep overbite, Permanent dentition, Maxillary first molar mesially inclined, Maxillary cuspids labially displaced, Loss of arch length due to premature loss of second deciduous molar.

\section{Contraindications}

Retrognathic profile, Numerous signs and symptoms of temperomandibular joint, Posteriorly and superiorly displaced condyles, Class II skeletal jaw bases, Skeletal open, Excess lower face height, Constricted maxillary arch, Dolicocephalic growth pattern, Class I or III molar relation, Dental open bite, Maxillary first molar distally inclined.

\section{Upper Molar Position}

This indicates or contraindicates molar distalization. Its mean value in patient's age in years plus $3 \mathrm{~mm}$ until growth is completed. In non-growing patients mean value is 18 $\mathrm{mm}^{26}$

\section{Appliances used for distalization:}

Headgear, Atikinson Buccal Bar, Herbst Appliance, Jasper Jumper, Pendulum And Pendex Appliance, Mini Distalization Appliances, Distal Jet Appliances, Wilson's Distalizing Arch (Bimetric Distalizing Arch), Compressed Springs, Repelling Magnetic Appliance, K-Loops, Sliding Jig etc. while for molar Distalization In lower Arch Lip Bumper, Modified Lingual Appliance, Distal Jet For Lower Molar can be used.

\section{Maxillary expansion}

Expansion can be divided into various arbitrary categories including orthodontic, passive, and orthopedic.

\section{Slow expansion devices}

\section{Active plates for arch expansion}

Active plates are most useful when only a few millimeters of space are needed. The framework of an active plate is a baseplastic made from acrylic or a similar (perhaps thermoplastic) material. This serves as a base in which screws or springs are embedded and to which clasps are attached. The active element of an expansion plate is almost always a jackscrew placed so that it holds the parts of the plate together. Opening the screw with a key then separates the sections of the plate.

\section{Quad Helix Appliance ${ }^{27}$ \\ Indications}

1. All cross- bites in which the upper arch needs to be widened

2. Mild expansion in the mixed dentition which frequently exhibit lack os space for the upper laterals and in which the long range growth forecast is favorable.

3. Class III - Expansion needed

4. Class II cases

5. Thumb sucking or Tongue thrusting cases

6. Cleft palate conditions either unilateral or bilateral

\section{Rapid maxillary expanders}

RME is an appliance of choice for expansion of maxillary halves when maxillary bases are constricted.

\section{Common appliances ${ }^{28}$}

1. Derirshweiler type: Tags are welded and soldered to the palatal aspects of the bands to provide attachment for the acrylic which is also extended to the palatal aspects of all non banded teeth, except the incisors.

2. Hass type: A length of $0.045 \mathrm{inch}(1.5 \mathrm{~mm})$ stainless steel wire is welded and soldered along the palatal aspects of the bands. The free ends are turned back and embedded in the acrylic base which stops short of the bands and teeth. A proprietary screw is set in the midline of the split acrylic base.

3. Issacson type: This appliance uses a special loaded screw called a Minne expander which is adapted and soldered directly to the bands without the use of acrylic. The screw may be reduced in length to suite narrow arches by shortening the spring, tube and rod.

4. Bidermann type: This appliance requires a special screw either Hyrax (Dentarum 602-813) Leaone 620 or Unitex 440-160. These have extension in heavy gauge wire where they are welded and soldered to the palatal aspects of the bands.

\section{Jackscrew Turn Schedules ${ }^{29}$}

Zimring and Isaacson recommend the following turn schedules:

1. Young growing patients two turns each day for the first 4 to 5 days, one turn each day for the remainder of RME treatment:

2. Adult (non growing) patient - because of increased skeletal resistance, two turns each day for the first 2 days, one turn each day for the next 5 to 7 days, and one turn every other day for the remainder of RME treatment.

\section{Surgically assisted maxillary expansion ${ }^{30}$ Indications}

1. A skeletal maxillomandibular transverse discrepancy greater than $5 \mathrm{~mm}$ (white patients)

2. Significant transverse maxillary deficiency associated with a narrow maxilla and wide mandible;

3. Failed orthodontic expansion; 
4. Necessity for a large amount $(>7 \mathrm{~mm})$ of expansion, or preference to avoid the potential increased risk of segmental osteotomies;

5. Extremely thin, delicate gingival tissue or presence of significant buccal gingival recession in the caninebicuspid region of the maxilla; and

6. Significant nasal stenosis.

\section{Uprighting of posterior teeth}

Tilted posterior teeth always occupy more space. Molars tend to tip mesially when the deciduous second molars are lost early or decay on the distal surface of this tooth is on/not restored at the appropriate time or with the ideal contour. A delayed eruption of the first or the second molar may also cause the posterior teeth to till mesially. Uprighting of molars can lead to an arch length gain of 1$1.5 \mathrm{~mm}$. fixed appliances are ideally used for the purpose. Space regainers or the various screw appliances are also used frequently. ${ }^{31}$

\section{Derotation of posterior teeth}

Rotated posterior teeth can help regain this space. The space regained varies upon the tooth concerned and the extent of rotation. For a similar degree of rotation, the molars occupy more space a s compared to premolars, whereas rotated anterior teeth occupy less space.

Derotation can be best achieved using a couple (forces equal in magnitude but opposite in direction) on the lingual and buccal surfaces of the tooth. Any fixed appliances system with a two point contact has more efficient rotation control. $^{31}$

\section{Proclination of Anterior}

Proclination of anterior teeth can be undertaken in cases where these teeth are retroclined or their proclination will not effect the soft tissue profile of the patient adversely or the stability of the result achieved.

Any of the proclination springs (" $Z$ " spring, mattress spring,etc.) or fixed appliances can be used for the purpose. $^{31}$

\section{Management of borderline skeletal malocclusions in non-growing individuals who require surgical intervention: \\ Use of temporary anchorage devices}

In borderline cases without severe skeletal discrepancies, orthodontic camouflage treatment may be an acceptable choice compared to orthognathic surgery ${ }^{32,33 .}$ The following scenarios in orthodontic camouflage therapy can be considered: extractions and active distalization in the upper jaw, extractions in both jaws, intermaxillary Class II mechanics, bite-jumping appliances, such as Herbst appliance, and a combination of these techniques.

Before TADs became available, distalization in the upper jaw had to rely on extra-oral traction using headgear and in which patient compliance was detrimental to the success of the therapy. With the introduction of TADs, patient cooperation became less important with the added benefit of almost absolute anchorage ${ }^{34}$ Of all orthodontic implants, miniscrews have gained considerable importance due to less surgical procedure and easy installation.

\section{Indications $^{35}$}

Mini implants are used most beneficially where three dimensional stable anchorage is needed, some of these situations are:

1. Where you cannot afford any movement of reactive units (maximum anchorage case)

2. Patient with several missing teeth making it difficult to engage posterior units

3. For difficult tooth movements, eg intrusion of anterior and posterior segments and distalisation

4. Where asymmetrical tooth movement is needed

5. To treat borderline cases with non extraction method

Doing extreme orthodontics when patient is not willing to undergo orthognathic surgery.

\section{Conclusion}

Any decision regarding the need for extraction of teeth during orthodontic therapy is not only dependent on the presence or absence of space in the dental arches. Other issues should be evaluated in order to achieve proper malocclusion correction, maintenance or improvement of facial aesthetics and result stability. In the available treatment modalities for border line case management a number of removable functional appliances have been developed, since the time which offers definitive advantages in growth modification to correct skeletal malocclusions.

Reproximation, expansion of arches, Molar distalization, derotation of posteriors, Proclination of anteriors and Uprighting of molars have all been the treatment modalities of yester years which are more commonly employed in today's treatment planning for management of borderline cases. Temporary Anchorage Devices / TADs revolutionized orthodontic treatment by decreasing the concern to anchorage, changing the extraction choices, bringing the most difficult tooth movements and providing better orthodontic treatment for some borderline orthognathic surgical patients.

\section{Source of Funding}

None.

\section{Conflict of Interest}

None.

\section{References}

1. Gust JE. A comparative analysis of borderline extraction cases treated in two phases utilizing rapid palatal expansion and lip bumper therapy Orthodontics. Saint Louis: Saint Louis University; 2006:115.

2. Baumrind S, Korn EL, Boyd RL, Maxwell R. The decision to extract: Part 1-Interclinician agreement. Am J Orthod Dentofacial Orthop 1996;109:297-309.

3. Drobocky OB, Smith RJ. Changes in facial profile during orthodontic treatment with extraction of four first premolars. 
Am J Orthod Dentofacial Orthop 1989;95:220-30.

4. Roberts CA, Subtelny JD. Use of the face mask in treatment of maxillary skeletal retrusion. Am J Orthod Dentofacial Orthop 1988;93(4):388-94.

5. Boley JC, Pontier JP, Smith S, Fulbright M. Facial changes in extraction and nonextraction patients. Angle Orthod 1998;68(1):539-46.

6. Burstone CJ. Diagnosis and treatment planning of patients with asymmetries. Semin Orthod 1998;4(4):153-64.

7. Strang RHW. A text-book of Orthodontia. 3rd ed. Philadelphia: Lea \& Febiger;1950.825.

8. Tanaka OM. Avaliação e comparação de métodos de diagnóstico do posicionamento das linhas medianas dentárias no exame clínico e nos modelos em gesso ortodôntico. [tese]. Curitiba: Pontifícia Universidade Católica do Paraná, 2000.

9. Enlow DH. Crescimento facial. $3^{\text {a }}$ ed. São Paulo: Artes Médicas; 1993. 553.

10. Paquette DE, Beattie JR, Johnston LE, Jr. A long-term comparison of nonextraction and premolar extraction edgewise therapy in "borderline" Class II patients. Am J Orthod Dentofacial Orthop 1992;102:1-14.

11. Telles CS, Urrea BEE, Barbosa CAT, Jorge EVF, Prietsch JR, Menezes LM, et al. Diferentes extrações em Ortodontia (sinopse). Rev SBO 1995;2(2):194-9.

12. Stephens CK, Boley JC, Behrents RG, Alexander RG, Buschang PH. Long-term profile changes in extraction and nonextraction patients. Am J Orthod Dentofacial Orthop 2005;128:450-457.

13. Oliver R, Knapman Y. Attitudes to orthodontic treatment. $\mathrm{Br}$ J Orthod 1985;12:179-88.

14. Ngan et al Perception of discomfort by patients undergoing orthodontic treatment. Am J Orthod Dentofacial Orthop 96:47-53

15. Haegglund, P.; Segerdal, S. The Sweedish style integrated Herbst appliance. J Clin Orthod 1997;31(6):378-90.

16. Pancherz H. The Herbst appliance: its biologic effects and clinical use. Am J Orthod 1985;87:1-20.

17. Coelho Filho, C. M. Emprego Clinic Do Aparelho Para Projecao Da Mandibular. R Dental Press. Orthodon Ortop Facial, Maringa 1998;3(5):69-130.

18. Brudon and Mc.Namara. Orthodontic \& orthopaedic treatment in mixed dentition.

19. Profitt W. Contemporary orthodontics. $3^{\text {rd }}$ edition. Elseviers Publication.

20. A new approach for orthopedic correction of Cl III. Chung, Jeong, Row, Yang - JCO 1999;33.

21. Skeletal changes associated with Extra - oral appliance. Angle Ortho 1989;59.

22. Peck H, Peck S. Reproximation (enamel stripping) as an essential orthodontic treatment ingredient, C.V, Mosby Co. St. Louis, 1975,513-522.

23. White L. The editor's corner. J Clin Orthod 1989:23:777-8.

24. Sheridan JJ Air-rotor stripping- J Clin Orthod 1985;19:43-59.

25. Graber LW, Vanarsdall RL, Vig KW: Orthodontics/ Current Principles and Techniques, Third Edition, Mosby, 760-1.

26. Ravinura Nanda: Biomechanics in clinical orthodontics: W.B.Saunders Company, 265-281.

27. Ivanovski V. Removable rapid palatal expansion appliance. J.C-0, 1985; 19:727-8.

28. Paloma Velazquez Rapid Maxillary Expansion. A study of the long term effects April 1996;V-109.

29. Timms D.J. Rapid Maxillary Expansion. $1^{\text {st }}$ edition. 1981. Quintessence publishing cor. Chicago.

30. Muge Sandikioglu. Skeletal \& Dental changes after maxillary expansion in the Mixed dentition, March 1997 V- 111.
31. Kharbanda OP. Text book of Diagnosis and management of malocclusion and dentofacial orthopedics. $1^{\text {st }}$ edition. Jaypee publishers.

32. Cassidy DW, Herbosa EG, Rotskoff KS, Johnston LE. A comparison of surgery and orthodontics in "borderline" adults with Class II, division 1 malocclusions. Am J Orthod Dentofacial Orthop 1993;104(5):455-70.

33. Mihalik CA, Proffit WR, Phillips C. Long-term follow-up of Class II adults treated with orthodontic camouflage: a comparison with orthognathic surgery outcomes. Am J Orthod Dentofacial Orthop 2003;123(3):266-78.

34. Daskalogiannakis J. Glossary of Orthodontic Terms. Quintessence Publishing, Hanover Park, IL; 2000.

35. Roberts WE, Smith RK, Zilberman Y, Mozsary PG, Smith RS. Osseous adaptation to continuous loading of rigid endosseous implants. Am J Orthod 1984;86:95-111.

How to cite this article: Shukla $P$, Thakral $R$, Gupta $S$, Nagar A, Borderline cases in orthodontics-A review, Indian J Orthod Dentofacial Res 2019;5(3):78-83. 